\title{
Factors Affecting Heart Rate Variability and Heart Rate Responses to Tilting in Infants Aged 1 and 3 Months
}

\author{
B.C. GALLAND, R.M. HAYMAN, B.J. TAYLOR, D.P.G. BOLTON, R.M. SAYERS, \\ AND S.M. WILLIAMS \\ Department of Paediatrics and Child Health [B.C.G., R.M.H., B.J.T., R.M.S.], Department of Physiology \\ [D.P.G.B.], Department of Preventive and Social Medicine [S.M.W.], Otago Medical School, Dunedin, \\ New Zealand
}

\section{ABSTRACT}

Heart rate variability (HRV) and heart rate (HR) responses following a $60^{\circ}$ head-up tilt were measured in 60 infants at 1 and 3 mo of age to investigate the effects on these of age, sleep state, sleep position, and mother's smoking status. HRV was determined from Poincaré plots of 500 sequential RR intervals to measure overall variability derived from the SDRR of this plot, and instantaneous variability derived from the SDARR. HR responses to the tilt were measured as changes in $R R$ interval length from rest to immediately following the tilt and again once a stable pattern was reached. SDRR and SD $\Delta$ RR increased 20 and $40 \%$, respectively, with age $(p<0.0001)$, SDRR was higher in active sleep (AS) than quiet sleep (QS, $+72 \%, p<0.0001)$ ) but both measures of variability (SDRR and SD $\Delta$ RR) were lower in the prone position compared with supine $(-18 \%, p<0.0001)$. However, several findings were dependent on the basal RR interval, thus the age effect disappeared once RR interval was taken into account, sleep state remained an important factor and the lower variability when prone now became a difference of
$-3 \%(p=0.034)$. The tilt generally provoked a reflex tachycardia followed by a bradycardia and settling to a stable HR level below, at, or above baseline within $30 \mathrm{~s}$. The more unusual responses were no HR change, sustained tachycardia or sustained bradycardia ( $15 \%$ of total). These were more likely to occur in younger infants $(p=0.008)$ and in $\operatorname{AS}(p<0.0001)$. No changes were seen in any of the cardiac indices related to maternal smoking status. The findings confirm several reports indicating that prone sleeping damps some physiologic responses. The data emphasize the need to consider basal heart rate, and sleep position as well as sleep state in autonomic function testing during infant sleep. (Pediatr Res 48: 360-368, 2000)
AS, active sleep
Abbreviations
QS, quiet sleep
HRV, heart rate variability
SIDS, sudden infant death syndrome

Autonomic dysfunction or autonomic maturational delay is a feature of some infants who succumb to SIDS (1-3). The prone sleeping position is strongly associated with SIDS (4-6). Previously we showed that measures of overall and instantaneous heart rate variability (HRV) were reduced in babies sleeping prone at $11 \mathrm{wk}$ of age (7). Measures were obtained using the beat-to-beat dynamics of heart rate control derived from Poincaré plots. Infants around this age are most vulnerable to SIDS but it appears positional differences in HRV may not be associated with a critical time in their development as similar data have been reported in preterm infants (8). Intrauterine conditions affected by maternal smoking can lead to

Received April 15, 1999; accepted December 22, 1999.

Correspondence: Dr Barbara Galland, Department of Paediatrics and Child Health, University of Otago, P.O. Box 913, Dunedin, New Zealand.

The study was funded by a grant from the Health Research Council of New Zealand and the Cot Death Association of New Zealand. RMH was funded by a scholarship from the Heart Foundation of New Zealand. alterations in the markers of autonomic nervous system function at birth (9), which may be important after birth when the infant has to respond to various cardio-respiratory challenges during sleep; maternal cigarette smoking during pregnancy is strongly associated with SIDS $(10,11)$.

In assessing autonomic function in infants, two noninvasive measures are commonly used: 1) beat to beat variations in basal heart rate, and 2) heart rate responses to a tilt test during sleep. As in adult studies, beat-to-beat heart rate variation is one of the most widely studied aspects of autonomic control using two basic mathematical analyses: time domain measures valuable for demonstrating trends over time, and frequency domain measures that assess dynamic properties of heart rate control (reviewed by Bernston et al., (12)). Physiologic correlates to explain changes in these derived measures are complex as the autonomic nervous system is highly integrated. In some cases specificity has been suggested, particularly in frequency domain measures where the relationship of the different fre- 
quency bands has been used to evaluate dynamic changes in the parasympathetic and sympathetic modulations of heart rate. The Poincaré plot has been introduced to assess beat-beat dynamics of heart rate; a scatter plot of one RR interval against the previous RR interval data displayed in a compact visual format readily interpretable in a qualitative and quantitative way (13). Quantitative data associated with these plots include mean heart rate, overall heart rate variance (SD of the beat intervals (SDRR)) and instantaneous variability (SD of the change between successive beat intervals (SD $\Delta R R)$ ) probably under vagal modulation $(14,15)$. Poincaré plot data has also been used to identify adult (16) and infant (17) cardiac abnormalities in various pathologic conditions and to discuss the physiologic mechanisms underlying SIDS (3).

Head-up tilting lowers blood pressure and the reflex heart rate response that follows is a measure of the altered balance of the two autonomic systems bringing blood pressure back to normal. The test has been used in the detection of vaso-vagal reactions in adults and children with syncope of unknown origin $(18,19)$ and recently in autonomic function testing of infants at high risk of SIDS with findings that have suggested sympathetico-vagal imbalance in some of these infants $(20-$ 22). The methodology for this test varies, in the timing and degree of tilts, age ranges studied, study conditions used and methods of analysis of the heart rate response (23). Analyses of the responses include 1) quantitative measures of the changes in heart rate from rest immediately following the tilt $(7,20)$ and the changes to a new stable rate $(24,25)$ and, 2) qualitative measures in terms of profiling the heart rate response (22). It has been shown that some infants who experienced apparent life-threatening events (ALTE) had a normal heart rate response to head-up tilting measured quantitatively, but abnormal by qualitative terms (22).

The objectives of this study were to evaluate changes in autonomic activity with respect to development of the infant, sleep state, sleep position, and maternal smoking status. The measures of autonomic activity used were beat-to beat variations in resting heart rate using Poincaré data, and quantitative and qualitative analyses of heart rate following a rapid $60^{\circ}$ head-up tilt.

\section{METHODS}

Subjects. Sixty full-term infants born at Queen Mary Maternity Unit at Dunedin Hospital were recruited for the study. Exclusion criteria were: living outside the Dunedin area, severe postnatal illness, major congenital abnormality or illness at the time of study. Two groups were recruited: 1) infants whose mothers did not smoke during pregnancy (nonsmokers' infants) and, 2) infants whose mothers smoked five or more cigarettes per day in the 2nd trimester (smokers' infants). Information related to the number of cigarettes smoked per day were obtained from a questionnaire to determine the average daily consumption during the $1 \mathrm{st}, 2 \mathrm{nd}$, and $3 \mathrm{rd}$ trimesters of pregnancy, and after pregnancy. Infants were studied at 2 ages: 1) within the $1 \mathrm{st}$ month (1-4 wk) and, 2) around 3 mo of age (11-14 wk).
Protocol. The babies were brought into Dunedin Hospital for a daytime nap in our research nursery. Room temperature was set between $20^{\circ}$ to $23^{\circ} \mathrm{C}$. Set-up for recordings involved placement of ECG electrodes (Kittycat ${ }^{(\mathbb{T I}}$ infant electrodes, Sentry Medical Products, CA, U.S.A.) and respibands around the chest and abdomen, and fitting of a harness (Jolly Jumper Inc., Cambridge, Canada). Following set-up, the infants were fed and then positioned prone or supine to sleep in a pram. The first position was chosen randomly.

The respiratory pattern was recorded by inductive plethysmography (Respitrace model 150; Respitrace Co., NY, U.S.A.). ECG electrodes were placed in a modified lead II position on the chest wall, which showed negative $\mathrm{T}$ waves. The respiratory and ECG signals were relayed through the integrated hardware/software system of the MacLab®) (ADInstruments Pty Ltd, Australia) at a sampling frequency of 500 $\mathrm{Hz}$.

Sleep state was determined by watching eye, mouth, hand, and respiratory trace movements based on that described for the two age groups by Guilleminault and Souquet (26). Generally quiet sleep (QS) contained regular breathing with no rapid eye movements or facial movements. Active sleep (AS) contained some rapid eye movements, irregular breathing and sometimes hand or mouth movements. Confirmation of sleep state was made from the variability of the ECG tachogram and/or Poincaré plots. An ECG was recorded for 500 beats for measurement of heart rate variability (HRV) and then infants were tilted to an angle of $60^{\circ}$ (head-up). The harness held them in the pram. The foot of the pram was modified to take support at a $60^{\circ}$ angle to the floor. The tilt took $2-3 \mathrm{~s}$ to complete. After $1 \mathrm{~min}$, the baby was then returned to a horizontal position and a minimum 3-min recovery period allowed before any further tests were done. Tilts were rarely repeated within $3 \mathrm{~min}$ of each other and the maximum eight tilts spanned out over 2 to $3 \mathrm{hr}$ of study. HRV measures and the tilt test were attempted twice in each sleep state in every baby. The baby was then turned over to the alternative sleep position and the procedures repeated. All 1-mo studies were performed over one daytime nap and were continuous with the exception of six infants $(10 \%)$ requiring a feed when sleep position was changed. The majority of 3-month studies were performed over two daytime naps (consecutive days or within $5 \mathrm{~d}$ of each other) and all were continuous naps. One infant routinely slept prone whereas the others slept on their side or back. There was no difficulty placing 1 mo infants to sleep prone but at 3 mo assistance with head positioning to the side was required just as they were falling off to sleep, and in some, repositioning was required during the nap. Both 1- and 3-mo studies began mid- to late morning $(\sim 1100 \mathrm{~h})$, a time when all the infants usually had their longest nap and continued for an average $2 \mathrm{~h} 30 \mathrm{~min}$ (1 mo) and $1 \mathrm{~h} 15 \mathrm{~min}$ (3 $\mathrm{mo})$.

HRV measurements. RR intervals were detected over 500 consecutive beats and Poincaré plots (scatter plots of the length of each RR interval plotted against the length of the previous RR interval) constructed using the heart rate variability extension 1.01 of the software program ADI Chart V.3.5.7 (ADInstruments Pty Ltd, Australia). HRV was quantitated from the scatter of Poincaré data according to Kamen and Tonkin (13) 
by measuring: 1) the SD of RR intervals projecting on to the $x$ axis (overall variance; SDRR); 2) the SD of the difference between consecutive RR intervals (instantaneous variability; $\mathrm{SD} \Delta \mathrm{RR}$ ), which relates to the variance of RR interval spreading perpendicularly along the line of identity (the diagonal line at an angle of $45^{\circ}$ to both axes). Examples of these plots and data are shown in Fig. 1. The pattern of change relates to the consistency of beat interval changes as heart rate increases or decreases. When the heart is beating with little variability, the points spread close to the line of identity. Points above this line
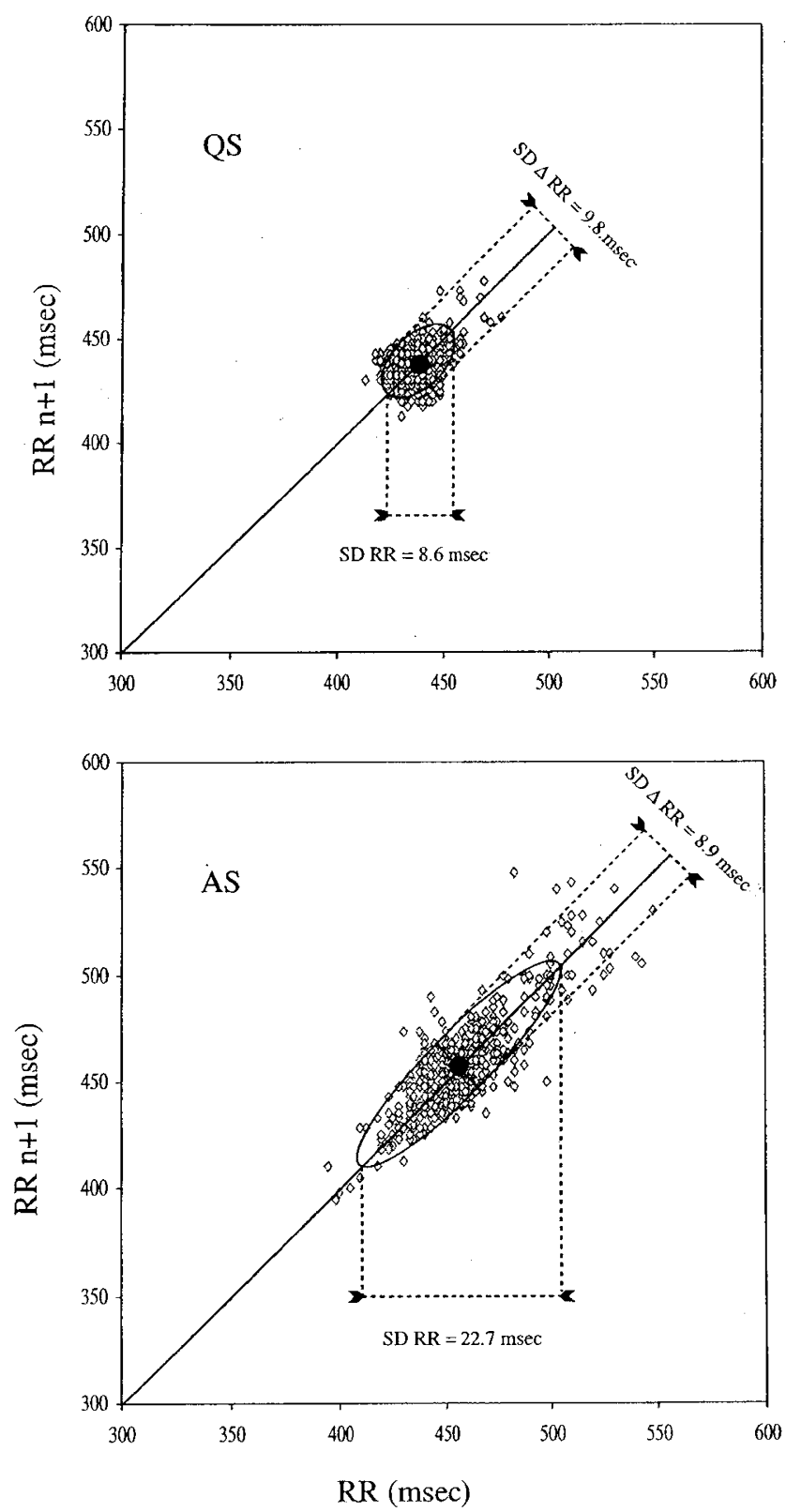

Figure 1. Poincaré plots from one subject during QS (top graph) and AS (bottom graph). The plots illustrate the graphic display and related indices quantified from this plot: 1) Overall variance: SDRR, the SD of RR intervals projecting on to the $x$ axis and 2) Instantaneous variance: SD $\Delta R R$, the SD of the difference between consecutive RR intervals that relates to the variance of RR interval spreading perpendicularly along the diagonal line. The AS graph illustrates a change from QS to an elongated Poincaré plot because SDRR has increased considerably more than SD $\Delta \mathrm{RR}$. indicate intervals longer than the previous ones, and below, shorter than the previous ones.

Tilt HR measurements. The HR response following the head-up tilt was measured 1 ) soon after the tilt to measure the reflex response and 2) when settled to a stable level above, at, or below baseline. Figure 2 gives an example of the RRinterval changes associated with the tilt. The reflex response was determined by the "ratio measure" and "profile measure." The ratio measure is a quantitative measure similar to that described by Fox and Mathews (20); maximum: minimum RR interval; the minimum interval was taken within 20 to 30 beats after the tilt, and the next maximum RR interval taken within the next 25 beats. This approach described the degree to which the bradycardia (maximum RR) exceeded the tachycardia (minimum RR). The profile measure took the minimum and maximum RRs expressed as ratio changes from baseline and plotted these against each other. Baseline RR represented a mean of the 40 beats before the tilt. This profile measure describes the degree to which individual responses are shifted from baseline and gives qualitative information of the heart rate profile following the tilt. Table 1 lists the criteria for defining the profile and the data points are illustrated in Figure 3. For the measurement of the stable HR response, the RR interval was averaged over five beats before and after the 30 -s mark, and the change in RR interval from baseline calculated.

Measurement of sigh and arousal response to the tilt. The presence of a sigh and apnea in response to the tilt (usually occurring within $5 \mathrm{~s}$ of initiating the tilt) was noted on the respiratory trace for later analyses. Infants were watched closely during the tilt to record an arousal score based on their behavioral response as: (0) no movement at all; (0.5) startle in response to tilt but remained asleep; (1) gross head and/or arm movement but no eyes open and settled quickly; (1.5) awake with gross head movement and/or eyes open but asleep again within 15-30 s and remained so on return to horizontal; (2) full awakening with eyes open and usually crying.

Ethics. The study protocol was approved by the Ethics Committee Otago, Southern Regional Health Authority, Dunedin, New Zealand. Informed written consent was obtained from the parent/s of infants who participated in the study.

Statistical methods. As there were multiple observations from each participant, all the data were used in the modeling with robust standard errors being used to calculate the $95 \%$ confidence intervals as provided in the STATA regression

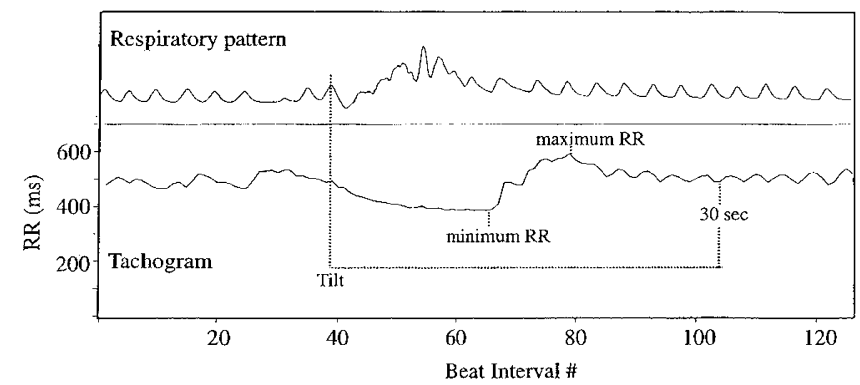

Figure 2. An example of the RR interval and respiratory pattern responses to a $60^{\circ}$ head-up tilt showing where data were taken for measurements of the ratio and profile measures (minimum and maximum RR) and the stable heart rate measure ( $30 \mathrm{~s}$ after the tilt). 
Table 1. Definition of profiles extracted from the RR response to the tilt

\begin{tabular}{|c|c|c|}
\hline & RR response defined & HR response \\
\hline Profile 1 & $\begin{array}{l}\text { A decrease in RR greater } \\
\text { than } 5 \% \text { of baseline and } \\
\text { remaining }\end{array}$ & Sustained $\uparrow \mathrm{HR}$ \\
\hline Profile 2 & $\begin{array}{l}\text { An increase in RR greater } \\
\text { than } 5 \% \text { of baseline and } \\
\text { remaining }\end{array}$ & Sustained $\downarrow$ HR \\
\hline Profile 3 & $\begin{array}{l}\text { Less than a } 5 \% \text { increase } \\
\text { and/or decrease in RR } \\
\text { from baseline }\end{array}$ & Flat response \\
\hline Profile 4 & $\begin{array}{l}\text { A greater than } 5 \% \\
\text { decrease in RR followed } \\
\text { by an increase to within } \\
5 \% \text { of baseline }\end{array}$ & $\begin{array}{l}\uparrow \text { HR followed } \downarrow \\
\text { HR (small reflex } \\
\text { response) }\end{array}$ \\
\hline Profile 5 & $\begin{array}{l}\text { A decrease followed by an } \\
\text { increase in RR (both } \\
\text { greater than } 5 \% \text { of the } \\
\text { baseline RR) }\end{array}$ & $\begin{array}{l}\uparrow \text { HR followed by } \\
\downarrow \text { HR (large reflex } \\
\text { response) }\end{array}$ \\
\hline
\end{tabular}

A 5\% change in RR interval represents approximately a 6-beat/min change in heart rate.

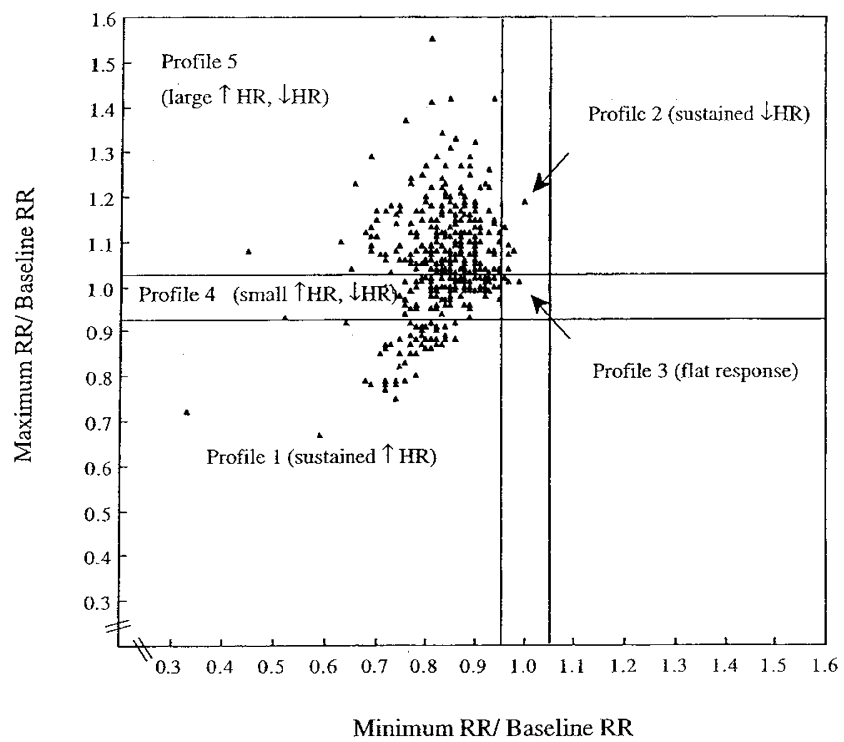

Figure 3. Plot of all the data showing scatter of the reflex RR response to the tilt. The data plotted are the minimum RR value against the maximum RR value (both expressed as a ratio of baseline RR i.e. RR before the tilt). The HR profiles are defined according to Table 1 .

procedure (Stata Statistical Software: Release 5.0, College Station, TX: Stata Corporation). The models included all main effects for age, sleep state, sleep position, and smoking status of the mother (nonsmoker or smoker), and statistically signif- icant two-way interaction effects. This means that the standard errors and the significance of the tests were based on the number of babies rather than the number of observations. The multiple observations were taken into account when the correlations of interest were calculated. To investigate whether there were any dose response effects of smoking, smoking status was also compared by rating the average number of cigarettes mother smoked during pregnancy on a 4-point scale, 0 indicating no smoking, 1 indicating less than 5 cigarettes/d, 2 indicating 5 to $10 / \mathrm{d}$, and 3 indicating $10-20 / \mathrm{d}$. Logistic regression was used to compare the sigh data, the arousal data and the heart rate profile codes for the variables concerned. Differences were considered statistically significant when the $p$ value $\leq 0.05$.

\section{RESULTS}

\section{Study Groups}

Information related to the characteristics of the infants studied and ages and weights at the different times of study are given in Table 2. The two study group infants did not differ in their gestational age at birth or age at time of study, but the smokers' group weighed less at birth and at the time of the two studies. Of the 26 smokers' infants, 1 mother smoked on average less than 5 cigarettes/d (during pregnancy), 15 smoked 5 to $10 / \mathrm{d}$, and 10 smoked $10-20 / \mathrm{d}$. All continued to smoke after pregnancy.

\section{Correlations between HRV and the tilt test HR response}

Correlations (taking into account the multiple observations) were made between the results of the two tests of autonomic function: HRV and the tilt test. There was a positive correlation between the overall HRV (SDRR) and the max: min RR interval ratio $(r=0.50, p<0.0001)$. Instantaneous HRV (SD $\Delta \mathrm{RR}$ ) and the max: min RR were also correlated positively $(r=0.65, p<0.0001)$. Therefore the higher the HRV, the greater the reflex heart rate response to the tilt.

Both test results were dependent on the baseline RR interval. Thus there was a positive correlation between the mean of the $40 \mathrm{RR}$ intervals measured before the tilt and the max: min RR $(r=0.60, p<0.0001)$, and a positive correlation between the mean of the $500 \mathrm{RR}$ intervals measured for HRV and SDRR $(r=0.66, p<0.0001)$ and $\mathrm{SD} \Delta \mathrm{RR}(r=0.84, p<0.0001)$. In terms of heart rate, this means that a lower heart rate was associated with a bigger heart rate reflex response to the tilt and more variability in rate.

Table 2. Group characteristics

\begin{tabular}{|c|c|c|c|c|c|c|c|}
\hline Group & $\begin{array}{c}\text { Sex } \\
(\mathrm{M} / \mathrm{F})\end{array}$ & $\begin{array}{l}\text { Gestation } \\
\text { (wk) }\end{array}$ & Birth weight (g) & $\begin{array}{l}\text { Age (days) at } 1 \\
\text { month study }\end{array}$ & $\begin{array}{l}\text { Weight at } 1 \text { month } \\
\text { study }(\mathrm{g})\end{array}$ & $\begin{array}{l}\text { Age (days) } \\
\text { at 3-mo } \\
\text { study }\end{array}$ & $\begin{array}{l}\text { Weight at 3-mo } \\
\text { study }(\mathrm{g})\end{array}$ \\
\hline $\begin{array}{l}\text { Non-smokers' infants } \\
\quad(n=34)\end{array}$ & 1.2 & $40(37-42)$ & $3610(2950-4480)$ & $22(15-28)$ & $4150(3330-4880)$ & $86(77-99)$ & $5969(4700-7180)$ \\
\hline $\begin{array}{l}\text { Smokers' infants } \\
\quad(n=26)\end{array}$ & 1.1 & $40(36-42)$ & $3480 *(2500-4040)$ & $20(15-26)$ & $3834 *(2430-4650)$ & $87(78-105)$ & $5513 *(4300-6490)$ \\
\hline
\end{tabular}

Values in parentheses represent ranges.

$* p<0.05$ vs corresponding factor for non-smokers' group. 


\section{HR and HRV}

Values for baseline HR and HRV measures according to age, sleep state, sleep position, and smoking status are given in Table 3. Heart rate (HR) decreased significantly with age (i.e. a significant increase in RR interval) was higher in AS compared with QS and higher when infants were sleeping prone as opposed to supine. HR was significantly more variable in the older infant, the biggest effect being on instantaneous HRV (SD $\Delta R R,+42 \%)$ compared with overall HRV (SDRR, $+21 \%$ ). HR was more variable in AS than QS, attributed solely to a $72 \%$ increase in overall variance (SDRR). An example of this sleep state difference is illustrated in Figure 1. HRV was significantly lower in the prone sleep position than supine (approximately 18\% less for both SDRR and SD $\Delta$ RR). This prone position effect was significant at both newborn and at 3 mo of age $(p<0.0001)$. All cardiac measures comparing the non-smoking and smoking groups were not significant and there was no dose-response effect of smoking during pregnancy.

Not shown in Table 3 are the adjustments made for the mean RR interval over the 500 beats, which resulted in deletion of the age effect for both measures of HRV $(p<0.05)$. The sleep state effect still held strongly $(+30 \%$ and $+10 \%$ for SDRR and $\mathrm{SD} \Delta \mathrm{RR}$, respectively, $p<0.0001)$ and the position effect held for SDRR but instead of a $-18 \%$ difference between supine and prone, the difference was now $-3 \%(p=0.034)$. There was an interaction of position with sleep state such that the decrease in SDRR between supine and prone was more significant in AS than QS $(-5 \%, p=0.017)$.

\section{Tilt test}

Sigh and arousal responses. The tilt resulted in a sigh in $49 \%$ of all tests and a sigh was 2.1 times $(\mathrm{CI}=1.4-2.2)$ more likely to occur in QS than AS $(p=0.004)$ but not influenced by any of the other factors. Sighs were mostly followed by an apnea $>2 \mathrm{~s}$ ( $94 \%$ of recorded sighs). The arousal response to the tilt was divided into two categories (codes 0 and 0.5 versus 1.0 to 2.0; little or no response versus gross movement and/or being woken to the test). Sleep state was the only factor associated with this: the odds ratio was $13.1(\mathrm{CI}=6.2-27.9)$, AS being the state the infants was more likely to respond with gross movement or waking $(p<0.0001)$. Numbers of tilts falling into each sleep state category are given in Table 4. Although position was not a significant factor, of the small number of tests identified as behaviorally waking the infant (codes 1.5 and 2.0,n=11), only one of these was in the prone position.

Ratio measure. Values for the tilt response measuring the ratio of the maximum $\mathrm{RR}$ interval to the minimum $\mathrm{RR}$ interval (max:min RR) are given in Table 5. No significant changes were seen in any of the cardiac indices between smokers' and nonsmokers' infants, and there was no dose-response effect of smoking during pregnancy. Not surprisingly, the effects of age, sleep state, and sleep position were in the same direction as those reported in Table 3, where the RR data were averaged over 500 consecutive beats. The ratio measure was effected by age only, being significantly higher at 3 than at 1 mo of age. There were no interaction effects. There was no correlation between the ratio measure and arousal code $(r=0.03, p=$

Table 3. Mean estimate values for measures of HRV with the differences for main effects

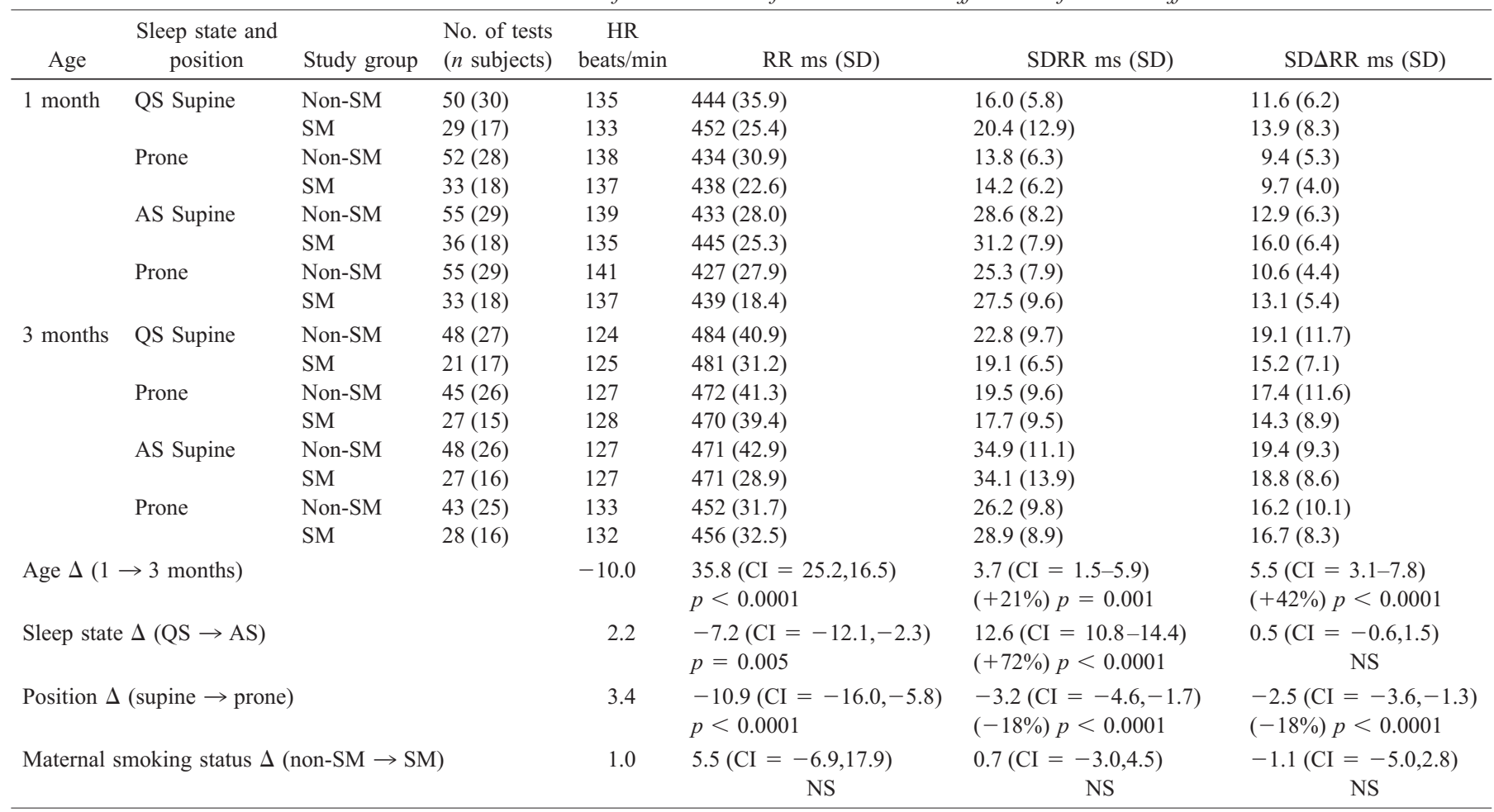

Non-SM refers to infants of non-smoking mothers and SM, infants of smoking mothers.

The differences $(\Delta)$ were adjusted for other factors in the model and the baseline centered at the mean. 
Table 4. Number of tilt tests in quiet and active sleep by arousal score and HR profile code

\begin{tabular}{lcccrrr}
\hline & \multicolumn{5}{c}{ Quiet sleep } & \\
\cline { 2 - 6 } Arousal Code & Profile 1 & Profile 2 & Profile 3 & Profile 4 & Profile 5 & Total \\
\hline 0 & 3 & 2 & 4 & 69 & 64 & 142 \\
0.5 & 3 & 1 & 0 & 25 & 14 & 43 \\
1.0 & 1 & 0 & 0 & 5 & 1 & 7 \\
1.5 & 0 & 0 & 0 & 0 & 0 & 0 \\
2.0 & 0 & 0 & 0 & 0 & 1 & 1 \\
Total & 7 & 3 & 4 & 99 & 80 & 193 \\
\hline Active sleep & & & & & & \\
0 & 3 & 0 & 0 & 10 & 14 & 27 \\
0.5 & 11 & 1 & 0 & 45 & 36 & 93 \\
1.0 & 27 & 1 & 0 & 29 & 26 & 83 \\
1.5 & 0 & 0 & 0 & 2 & 1 & 3 \\
2.0 & 4 & 0 & 0 & 1 & 2 & 7 \\
Total & 45 & 2 & 0 & 87 & 79 & 213 \\
\hline
\end{tabular}

Data are combined for age, sleep position, and study groups.

Arousal codes are summarized as: 0 , no movement; 0.5 , startle; 1 , gross movement; 1.5 , awake with gross movement but back to sleep within $15-30 \mathrm{~s}$; 2, full awakening.

HR profile codes are: 1, Sustained $\uparrow$ HR; 2, Sustained $\downarrow$ HR; 3, flat response; 4, $\uparrow$ HR followed by $\downarrow$ HR (small reflex response); 5, $\uparrow \mathrm{HR}$ followed by $\downarrow$ HR (large reflex response).

$0.28)$. The measured ratio was independent of the number of tilts performed i.e. after controlling for age, there was no directional change in response with tilt order $(p=0.92)$. The ratio measure was also analyzed when no movement occurred during the tilt i.e. data with arousal code 0 only. Age remained the only significant factor $(p=0.026)$ still showing a higher ratio at 3 mo than $1 \mathrm{mo}$ of age $(0.06(\mathrm{CI}=0.007-1.09))$.
Profile measure. HR profiles 1, 2, and 3 (flat response and sustained tachycardia or bradycardia) were least prevalent ( $15 \%$ of total). Comparisons to ascertain the likelihood of a particular factor associated with the least prevalent HR responses were as follows: younger infants were 1.14 times $(\mathrm{CI}=1.02-1.25)$ more likely than older infants to respond in this way $(p=0.008)$, and in all infants, the chances were 1.5 times $(\mathrm{CI}=1.4-1.6)$ more in AS compared with QS $(p<$ $0.0001)$. Numbers of tilts falling into each profile category are given in Table 4. Sleep position or smoking status (grouped or dose-rated) had no effect on the response. The profile measure was the only one of the three HR measures that was significantly effected by a sigh in the tilt maneuver: positive correlation with a reflex heart rate response (profiles 4 and 5) $(r=$ $0.32, p=0.021)$. The profile measure was independent of the number of tilts performed $(p=0.25)$. When no movement occurred during the tilt, the significant age and sleep state effects disappeared ( $p=0.24$ and $p=0.39$, respectively) and no new significant factors emerged.

Stable HR response. Data are given alongside the ratio data in Table 5. The stable HR response was influenced by sleep state only: the $\Delta$ RR from baseline was greater in AS than QS. In terms of a heart rate change, in AS, heart rate increased from baseline by 5.6 . beats $/ \mathrm{min}(p<0.001)$, and in QS, decreased by a small but significant amount $(-1.0$ beats $/ \mathrm{min}, p=0.04)$. When data were analyzed for tilts involving no movement $\Delta$ RR was still greater $(p=0.016)$ in AS than QS $(-17.6$ $(\mathrm{CL}=-31.7,-3.4))$ but again there were still no effects of age, position or smoking status. There was a correlation between the arousal code and stable HR response such that the

Table 5. Mean estimate values for measures of tilt test with the differences for main effects

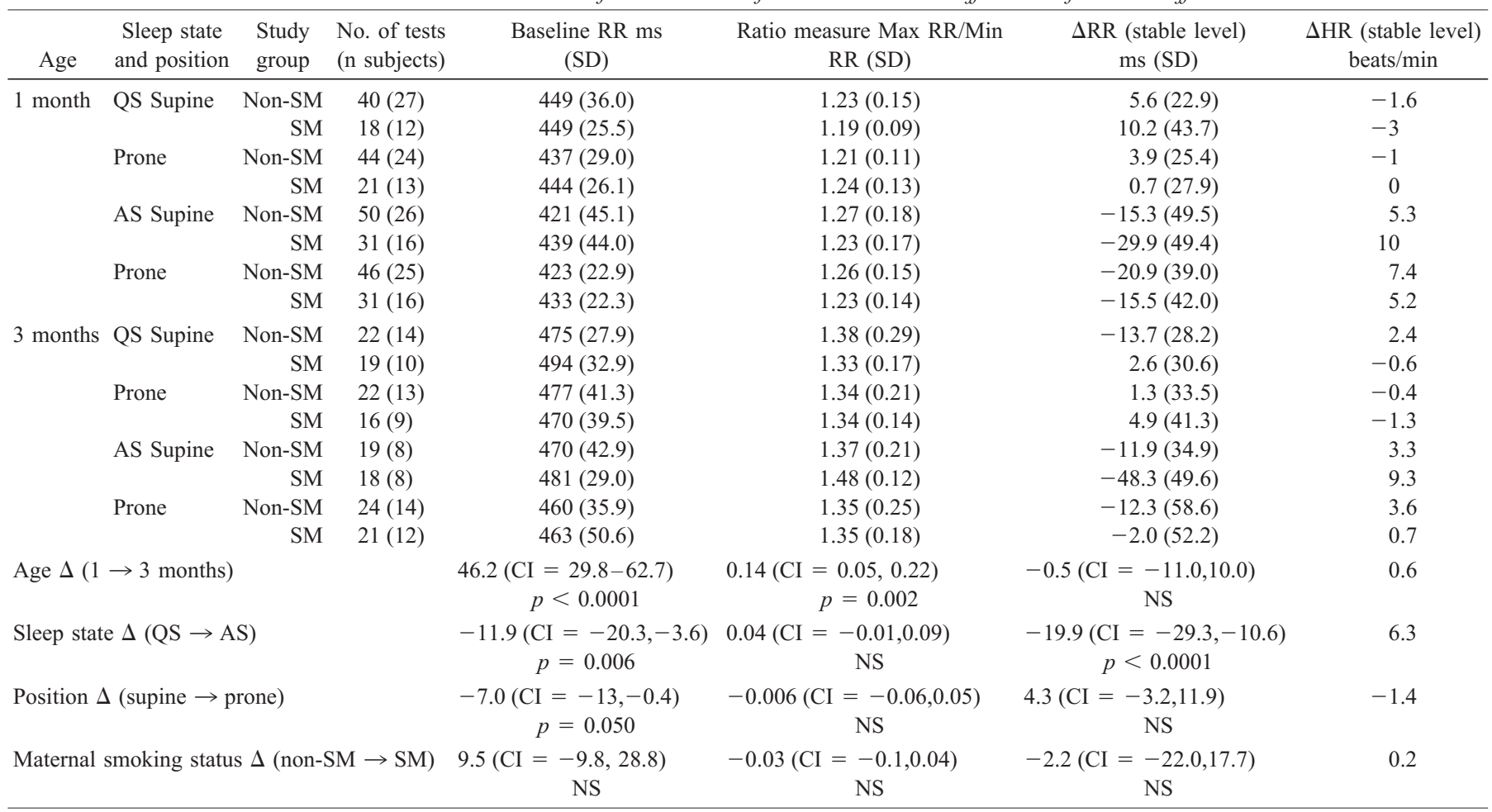

Non-SM refers to infants of non-smoking mothers and SM, infants of smoking mothers.

The differences $(\Delta)$ were adjusted for other factors in the model and the baseline centered at the mean. 
higher the arousal code, the higher the stable heart rate change $(r=0.30, p=0.03)$. In tests where infants showed little or no arousal response (arousal code 0 and 0,5 ) to the tilt, the HR responses were 4.6 times more likely to profile 1,2 , or 3 ( $p<$ $0.0001)$.

\section{DISCUSSION}

The main findings of this study were that autonomic measures of HRV and heart rate responses to head-up tilting showed changes consistent with a maturing autonomic nervous system over 1 to 3 mo of age. Furthermore, the positive correlation found between these two measures gives us confidence to use the measures independently to assess the autonomic status of an individual infant. Other main findings were that HRV was reduced in the prone sleep position compared with supine, and no changes were seen in any of the cardiac indices related to maternal smoking status.

Age differences. The increased heart rate variability from 1 to 3 moths of age was partly influenced by the lower heart rate of the older infants as this age effect disappeared once the RR interval was adjusted for. Similar findings have been reported by Schechtman et al. using analyses of Poincaré data (SDRR vs SD $\Delta$ RR) from infants aged $1 \mathrm{wk}$ to 6 mo (27). These same authors also described increased variability in infants over 1 to 3 mo of age, a plateau at 3-4 mo of age, and a further increase at 6 mo of age. In addition to age-related changes in heart rate contributing to the increase in variability, an increase in the respiratory component to heart rate variability (sinus arrhythmia) must also impact on this (28) as respiratory rate becomes slower and tidal volume increases with maturation.

Head-up tilting has been used most frequently to test maturation of baroreflex activity in the neonatal period as reviewed by Gootman and Gootman (23) and more recently for studies in older infants investigating autonomic differences in infants at high risk of SIDS $(20-22)$. The pattern of response to venous pooling, which decreases cardiac venous return, filling pressure and cardiac output, leads to reflex activation of the sympathetic nervous system and an immediate increase in heart rate. Venoconstriction restores right atrial filling pressures leading to a sequence of events that raises arterial pressure. A fast tilt maneuver results in a rebound bradycardia as an overshoot response to the initial tachycardia (29) as shown in Figure 2. We found the ratio measure to be higher in older infants suggesting a larger reflex response to the tilt, findings that were reproduced by defining the profile of the response but not apparent once the heart rate reached a stable level. However with a rapid tilt, sighs, apneas, and movement are common and some stress the importance of measuring heart rate responses only in the absence of these $(24,25)$. By excluding movement in our analysis, the maturational effect remained for the reflex response. The profile measure adds information to the ratio measure, which in describing the immediate response, only describes the extent to which the bradycardia exceeds the tachycardia (if indeed a tachycardia has occurred at all).

Sleep state. The higher variability in active sleep compared with quiet sleep reflects both a more variable respiratory pattern and a sympathetic predominance in this sleep state (30).
In adult studies, an increase in the ratio of $\mathrm{SDRR} / \mathrm{SD} \Delta \mathrm{RR}$ means an increase in sympathetic tone (16) and it has been shown that a decrease in the ratio results from chemical thoracic sympathectomy (31). Our study recorded a higher ratio of $\mathrm{SDRR} / \mathrm{SD} \Delta \mathrm{RR}$ ratio in active compared with quiet sleep since SD $\Delta$ RR was unaffected by state and SDRR increased markedly. Following the head-up tilt, the stable HR response was very strongly associated with sleep state, both with and without movement in the analysis. In contrast, studies of preterm and term infants slowly tilted head-up to $30^{\circ}$ or $60^{\circ}$ (so as not to induce sighs or movement), found no association between the stable heart rate change and sleep state $(24,25)$.

Edner et al. (22) identified a subset of babies ALTE infants who had profiles similar to that of profile 2 (sustained HR decrease) and 3 (flat response) in response to a rapid tilt. No age-matched controls responded with profiles 2 or 3 , although one infant had profile 1 . Sleep state was possibly not controlled for other than a mention that infants were quietly asleep during the tests. In the present study of a much larger number of infants, we have shown that profiles 1, 2, and 3 were least prevalent but nevertheless represented $15 \%$ of all responses and AS was the state most commonly associated with these profiles. Our infants had no history of ALTE. We are reporting on a range of responses reflecting normal population distribution.

Sleeping position. The overall effects of sleeping position on reducing $\mathrm{HRV}$ in 3-mo-old infants sleeping prone confirmed findings from a previous study of ours (7). However the finding that HRV in 1-mo-old infants was also reduced in the prone position is new, suggesting that this is an effect of position per se rather than occurring at a critical time during development. The importance of taking into account the baseline RR interval was emphasized here where the position effect was reduced considerably from a difference in HRV between supine and prone of $-18 \%$ to $-3 \%$ but was still significant. The finding of reduced HRV prone is consistent with the documented behavioral and physiologic characteristics of this position. In active sleep, prone positioning compared with supine results in less movement and fewer sighs in infants aged 2.5 and 5 mo (32). Such features would be expected to reduce HRV. The respiratory rate data related to our study showed that prone sleeping decreased rate by a significant five breaths/min at the 1 mo age but was unchanged at 3 mo (unpublished). A decrease in respiratory rate would increase rather than decrease the instantaneous component of HRV attributed to sinus arrhythmia (28).

The higher baseline heart rate recorded prone may reflect the observation that prone positioning reduces the exposed surface area available for heat loss $(33,34)$ and skin temperature rises (32). Experimental data from neonatal puppies show a decrease in parasympathetic activity, working through a non-central pathway, in response to a rise in temperature. This could conceivably mean that a slight rise in the body temperature of an infant could cause inhibition of vagal activity (35).

Sleep position did not alter the tilt heart rate reflex response despite a higher baseline heart rate recorded prone. The heart rate changes following a tilt include other physiologic inputs that are poorly quantifiable. More direct measures of the tilt response such as changes in blood pressure or blood flow may 
be more useful. White et al. (36) in a study of 25 newborn infants reported a greater fall in blood pressure in infants sleeping prone compared with supine suggesting a reduction in vasomotor tone in the prone position.

Although position did not affect arousal overall, of the small number of tilts that did result in behavioral waking, only one occurred in the prone position adding support to the consensus that prone sleeping induces a higher arousal threshold $(7,37)$. AS is the state that infants were much more likely to be provoked to arouse from, confirming the findings of other studies of infant arousal that have used a variety of different stimuli $(7,38,39)$.

Maternal smoking status. The finding that the smoking status of the infant's mother had no influence on any of the measures of autonomic function is perhaps not surprising, given the evidence that markers for autonomic dysfunction at the time of birth and after are apparent following conditions associated with chronic uterine stress $(9,40)$. Prenatal or postnatal histories of the smoking mothers did not indicate that any of the infants had been subjected to chronic stress. It is possible that a study of infants exposed to heavier smoking levels may have revealed a difference in autonomic responsiveness. Smoking groups were rated according to the average number of cigarettes smoked during pregnancy, not after, because: 1) Autonomic differences in infants exposed to smoking and chronic stress are apparent in the last trimester of pregnancy (9) and soon after birth (41) and; 2) animal studies show that exposure to nicotine in utero alters the development of nicotinic receptors in the brain; the effect persists into the postnatal period and may alter postnatal cardiac and respiratory control $(42,43)$.

Limitations of the study. Although every attempt was made to standardize the feeding, we acknowledge that time after feeding and feeding type may be important uncontrolled sources of variance that could have effected our responses through alterations in heart rate, energy expenditure, and sleep state organization (44-46). Although the time of day of study can effect heart rate (47), we controlled for this to a certain extent by carrying out studies over a similar part of the day.

Conclusion. This study provides normal heart rate data related to the tilt beyond the neonatal period and emphasizes the importance of controlling for basal heart rate, sleep position, sleep state, and age in autonomic function testing in infancy. Our data also demonstrate reductions in overall and instantaneous heart rate variability in prone sleeping infants confirming several reports that now indicate that this position could dampen an infant's ability to respond appropriately to the various cardio-respiratory challenges of sleep.

Acknowledgments. The authors thank the parents whose babies participated in the study.

\section{REFERENCES}

1. Taylor BJ, Williams SM, Mitchell EA, Ford RPK 1996 Symptoms, sweating and reactivity of infants who die of SIDS compared to community controls. J Paediatr Child Health 32:316-322

2. Schwartz PJ, Stramba-Badiale M, Segantini A, Austoni P, Bosi G, Giorgetti R, Grancini F, Marni ED 1998 Prolongation of the QT interval and the sudden infant death syndrome. N Engl J Med 338:1709-1714
3. Schechtman VL, Raetz SL, Harper RK, Garfinkel A, Wilson AJ, Southall DP, Harper RM 1992 Dynamic analysis of cardiac R-R Intervals in normal infants and in infants who subsequently succumbed to the sudden infant death syndrome. Pediatr Res 31:606-612

4. Mitchell E, Scragg R, Stewart A, Becroft D, Taylor B, Ford R, Hassall I, Barry DM, Allen EM, Roberts AP 1991 Results from the first year of the New Zealand cot death study. NZ Med J 104:71-76

5. Dwyer T, Ponsonby A-LB, Newman NM 1991 Prospective cohort study of prone sleeping position and sudden infant death syndrome. Lancet 337:1244-1247

6. Fleming PJ, Gilbert RE, Azaz Y, Berry PJ, Rudd P, Stewart A, Hall E 1990 Interaction between bedding and sleeping position in the sudden infant death syndrome: a population based case-control study. BMJ 301:85-89

7. Galland BC, Reeves G, Taylor BJ, Bolton DP 1998 Sleep position, autonomic function, and arousal. Arch Dis Child 78:F189-194

8. Sahni R, Schulze KF, Kashyap S, Ohira-Kist K, Myers MM, Fifer WP 1999 Body position, sleep states, and cardiorespiratory activity in developing low birth weight infants. Early Hum Dev 54:197-206

9. Van Reempts PJ, Wouters A, De CW, Van AKJ 1996 Clinical defense response to cold and noise in preterm neonates after intrauterine conditions associated with chronic stress. Am J Perinatol 13:277-286

10. Mitchell EA, Tuohy PG, Brunt JM, Thompson JM, Clements MS, Stewart AW, Ford RP, Taylor BJ 1997 Risk factors for sudden infant death syndrome following the prevention campaign in New Zealand: a prospective study. Pediatrics 100:835-840

11. Alm B, Milerad J, Wennergren G, Skjaerven R, Oyen N, Norvenius G, Daltveit AK, Helweg-Larsen K 1998 A case-control study of smoking and sudden infant death syndrome in the Scandinavian countries, 1992 to 1995. The Nordic Epidemiological SIDS Study. Arch Dis Child 78:329-334

12. Berntson GG, Bigger JT, Jr., Eckberg DL, Grossman P, Kaufmann PG, Malik M, Nagaraja HN, Porges SW 1997 Heart rate variability: origins, methods, and interpretive caveats. Psychophysiology 34:623-648

13. Kamen PW, Tonkin AM 1995 Application of the Poincare plot to heart rate variability; a new measure of functional status in heart failure. Aust NZ Med J 25:18-26

14. Tulppo MP, Makikallio TH, Takala TE, Seppanen T, Huikuri HV 1996 Quantitative beat-to-beat analysis of heart rate dynamics during exercise. Am J Physiol 271:H244252

15. Malik M, Camm AJ 1993 Components of heart rate variability-what they really mean and what we really measure. Am J Cardiol 72:821-822

16. Woo MA, Stevenson WG, Moser DK, Trelease RB, Harper RM 1992 Patterns of beat-to-beat heart rate variability in advanced heart failure. Am Heart J 123:704-710

17. Woo MS, Woo MA, Gozal D, Jansen MT, Keens TG, Harper RM 1992 Heart rate variability in congenital central hypoventilation syndrome. Pediatr Res 31:291-296

18. Raviele A, Gasparini G, Di Pede F, Delise P, Bonso A, Piccolo E 1990 Usefulness of head-up tilt test in evaluating patients with syncope of unknown origin and negative electrophysiologic study. Am J Cardiol 65:1322-1327

19. Samoil D, Grubb BP, Kip K, Kosinski DJ 1993 Head-upright tilt table testing in children with unexplained syncope. Pediatrics 92:426-430

20. Fox GPP, Matthews TG 1989 Autonomic dysfunction at different ambient temperatures in infants at risk of sudden infant death syndrome. Lancet 2(8671):1065-1067

21. Mathews TG 1992 The autonomic nervous system- a role in sudden infant death syndrome. Arch Dis Child 67:654-656

22. Edner A, Katz-Salamon J, Lagercrantz H, Milerad J 1997 Heart rate response profiles during head upright tilt test in infants with apparent life threatening events. Arch Dis Child 76:27-30

23. Gootman PN, Gootman N 1992 The assessment of the autonomic nervous system. In: Eyre JA (ed) Neurophysiological Examination of the Newborn. Cambridge Univ Press, New York, pp 168-194

24. Thoresen M, Cowan F, Walloe L 1991 Cardiovascular responses to tilting in healthy newborn babies. Early Hum Dev 26:213-222

25. Finley JP, Hamilton R, MacKenzie MG 1984 Heart rate response to tilting in newborns in quiet and active sleep. Biol Neonate 45:1-10

26. Guilleminault C, Souquet M 1979 Sleep states and related pathology. In: Korobkin R, Guilleminault C (eds) Advances in Perinatal Neurology. Spectrum Publications Inc, New York, pp 225-247

27. Schechtman VL, Harper RK, Harper RM 1993 Development of heart rate dynamics during sleep-waking states in normal infants. Pediatr Res 34:618-623

28. Laude D, Weise F, Girard A, Elghozi JL 1995 Spectral analysis of systolic blood pressure and heart rate oscillations related to respiration. Clin Exp Pharmacol Physiol 22:352-357

29. Sundkvist G, Lilja B 1983 Effect of the degree and speed of tilt on the immediate heart rate reaction. Clin Physiol 3:381-386

30. Baccelli G, Guazzi M, Mancia G, Zanchetti A 1969 Neural and non-neural mechanisms influencing circulation during sleep. Nature 223:184-185

31. Hirose M, Imai H, Ohmori M, Matsumoto Y, Amaya F, Hosokawa T, Tanaka Y 1998 Heart rate variability during chemical thoracic sympathectomy. Anesthesiology 89:666-670

32. Skadberg BT, Markestad T 1997 Behaviour and physiological responses during prone and supine sleep in infancy. Arch Dis Child 76:320-324

33. Nelson EAS, Taylor BJ, Weatherall IL 1989 Sleeping position and infant bedding may predispose to hyperthermia and sudden infant death syndrome. Lancet i:199-201

34. Bolton DPG, Nelson EAS, Taylor BJ, Weatherall IL 1996 Thermal balance in infants. J Appl Physiol 80:2234-2242 
35. Pickoff AS, Stolfi A, Campbell P 1997 Temperature dependency of the vagal chronotropic response in the young puppy: An 'environmental-autonomic interaction'. J Auton Nerv Syst 64:107-114

36. White M, Beckett M, O'Regan M, Matthews T 1993 Autonomic function and SIDS Acta Paediatr Suppl 389:105-106

37. Franco P, Pardou A, Hassid S, Lurquin P, Groswasser J, Kahn A 1998 Auditory arousal thresholds are higher when infants sleep in the prone position. J Pediat $132: 240-243$

38. Campbell AJ, Bolton DPG, Taylor BJ, Sayers RM 1998 Responses to an increasing asphyxia in infants: effects of age and sleep state. Respir Physiol 112:51-58

39. Read PA, Horne RS, Cranage SM, Walker AM, Walker DW, Adamson TM 1998 Dynamic changes in arousal threshold during sleep in the human infant. Pediatr Res 43:697-703

40. Van Reempts PJ, Wouters A, De CW, Van AKJ 1997 Stress responses to tilting and odor stimulus in preterm neonates after intrauterine conditions associated with chronic stress. Physiol Behav 61:419-424

41. Sindberg EP, Gennser G, Lindvall R, Nilsson K 1984 Acute effects of maternal smoking on fetal heart beat intervals. Acta Obstet Gynecol Scand 63:385-390
42. Hagino N, Lee JW 1985 Effect of maternal nicotine on the development of sites for [3H]nicotine binding in the fetal brain. Int J Develop Neurosci 3:567-571

43. Slotkin TA, Orband-Miller L, Queen KL 1987 Development of [3H] nicotine binding sites in brain regions of rats exposed to nicotine prenatally via maternal injections or infusions. J Pharm Exp Ther 242:232-237

44. Schulze K, Kairam R, Stefanski M, Sciacca R, Bateman D, Dell R, James LS 1981 Spontaneous variability in minute ventilation oxygen consumption and heart rate of low birth rate infants. Pediatr Res 15:1111-1116

45. Butte NF, Jensen CL, Moon JK, Glaze DG, Frost JD, Jr 1992 Sleep organization and energy expenditure of breast-fed and formula-fed infants. Pediatr Res 32:514-519

46. Myers MM, Fifer WP, Schaeffer L, Sahni R, Ohira-Kist K, Stark RI, Schulze KF 1998 Effects of sleeping position and time after feeding on the organization of sleep/wake states in prematurely born infants. Sleep 21:343-349

47. Amemiya F, Vos JE, Prechtl HF 1991 Effects of prone and supine position on heart rate, respiratory rate and motor activity in fullterm newborn infants. Brain Dev $13: 148-154$ 